\title{
Periodontal status of rheumatoid arthritis patients in khartoum state
}

\author{
Safa K Abdelsalam¹, Nada T Hashim² ${ }^{2 *}$ Emitithal M Elsalamabi ${ }^{3}$ and Bakri G Gismalla ${ }^{4}$
}

\begin{abstract}
Background: Few studies have investigated the periodontal condition among Rheumatoid arthritis in Sudan. The present study described the periodontal condition among Sudanese patients suffering from rheumatoid arthritis and to compare them with those of non-rheumatic subjects.

Methods: A group of eighty rheumatoid arthritis patients was selected from Patient's Rheumatoid Clinics in Khartoum State during the period of January to May 2010. A control group of eighty patients with the same age and gender was selected for the study. Both Rheumatoid arthritis patients and the control group were examined for their plaque index, gingival index, and clinical attachment loss.

Results: The results revealed that there were no significant differences in plaque and gingival index among study and control groups, with mean plaque index of $(1.25 \pm 0.4)$ for patients and $(1.17 \pm 0.28)$ for the control group ( $p$ value is 0.3597$)$. The mean gingival index was $(1.2 \pm 0.24)$ for the patients and $(1.2 \pm 0.33)$ for the control $(p=$ is 0.3049). The results showed statistically significant differences in clinical attachment loss between study and control groups, with mean clinical attachment loss of $(1.03 \pm 0.95)$ for the study group and $(0.56 \pm 0.63)$ for the control group ( $p=0.0002$ ). The study revealed that no association exists between the type of drug used to treat rheumatoid arthritis (NSAIDs \& DMARDs) and the periodontal parameters (plaque index, gingival index, and clinical attachment loss).
\end{abstract}

Conclusion: A significant relationship between periodontal disease and Rheumatoid Arthritis does exist, but no difference between plaque and gingival index has been detected among study and control groups.

Keywords: periodontal health, Rheumatoid arthritis

\section{Background}

The oral cavity is thought to be the window to the body because oral manifestations accompany many systemic diseases [1]. Periodontitis is a common disease worldwide that has a primary bacterial etiology and is characterized by dysregulation of the host inflammatory response which eventually results in soft and hard tissue destruction $[2,3]$

Rheumatoid arthritis (RA) is a chronic destructive inflammatory disease characterized by the accumulation and persistence of an inflammatory infiltrate in the synovial membrane that leads to synovitis and the destruction of the joint architecture [2].

\footnotetext{
* Correspondence: nadatawfig@yahoo.com

2Department of Periodontology, Khartoum North Dental Teaching Hospital, Khatroum, Sudan

Full list of author information is available at the end of the article
}

Rheumatoid arthritis (RA) occurs worldwide with prevalence of $1 \%$ in the population, most common in females [4], affecting women three times more than men $[5,6]$. It is estimated that arthritis and other rheumatic conditions affect 42.7 million Americans [7] with prevalence of 0.5 to $1 \%$ in Western population [8].

While the etiology of these two diseases may differ, the underlying pathogenic mechanisms are remarkably similar and it is possible that individuals manifesting both periodontitis and RA may suffer from a unifying underlying systemic dysregulation of the inflammatory response [2]. There is almost universal acceptance that a variety of cytokines and matrix metalloproteinases (MMPs) are upregulated and intimately involved in the pathogenesis of both periodontitis and RA; many of these effector molecules appear to be common to both diseases [3]. High levels of proinflammatory cytokines,
Ciomed Central

(C) 2011 Hashim et al; licensee BioMed Central Ltd. This is an open access article distributed under the terms of the Creative Commons Attribution License (http://creativecommons.org/licenses/by/2.0), which permits unrestricted use, distribution, and reproduction in any medium, provided the original work is properly cited. 
including IL-1b and tumor necrosis factor-alpha (TNFa), and low levels of cytokines which suppress the immunoinflammatory response, such as IL-10 and transforming growth factor-b (TGF-b), have been detected in periodontitis as well as in Rheumatoid Arthritis [9].

Natural history studies of periodontal disease in humans indicate the presence of three distinct subpopulations: [10].

1) no progression of periodontal disease, in which around $10 \%$ of the population manifest very little or no disease which is of particular consequence to dentition; 2) moderate progression, affecting around $80 \%$ of the population and representing a very slowly progressing form of disease that generally can be easily managed via routine therapies; and 3) rapid progression, affecting approximately $8 \%$ of individuals whereby extensive periodontal destruction occurs which can be very difficult to control.

On the other hand, three types of disease manifestations can also be observed in RA populations:

1) Self-limited: in these cases, individuals originally presenting for RA have no evidence of disease 3 to 5 years later; [11].

2) Easily controlled: the disease is relatively easily controlled with only non-steroidal anti-inflammatory drugs (NSAIDs); [12]

3) Progressive: these patients generally require secondline drugs, which often still do not fully control the disease [13].

It must be recognized that periodontitis differs in one significant way from RA through our understanding that the subgingival biofilm is a key etiologic factor in periodontitis. Unlike periodontal disease, no specific bacterial etiology has been identified for RA. Thus, while host modifications of disease processes are possible for periodontitis, controlling the bacteria that cause periodontal infections remains a significant focus for periodontal treatment and prevention. Host modification can be only an adjunct treatment for periodontitis. However, until an etiologic factor can be found for RA, host modification remains the primary treatment [3].

Currently, the first line of treatment for RA is NSAIDs such as aspirin, naproxen, diclofenac, and ibuprofen. Their mechanism of action through the inhibition of Cyclooxygenase (COX) synthesis produces both analgesic and antipyretic properties. Although these medications are effective in reducing the pain symptoms in RA, they do not significantly alter its course [14].

The use of NSAIDs for the treatment of chronic periodontitis has been studied over the past 20 years [15]. While the results appear promising, the widespread clinical use of these medications to alter the course of periodontitis has not been universal. Their use for the management of periodontitis appears to be a "rebound" effect to baseline following a cessation of the medication [16].

With the discovery of two COX enzymes responsible for PGE2 production, designated COX-1 and COX-2, a variety of COX-2 inhibitors have been studied for their potential to stop or slow down bone resorption. One of the first COX-2 inhibitors developed, Tenidap, has been shown to inhibit not only cyclooxygenase and PGE2 production but also IL-1, IL-6, and TNF-a production. To date, the potential of COX-2 inhibitors to modify bone resorption in periodontitis have not been thoroughly studied [3].

In contrast to NSAIDS, which do not significantly alter the course of RA, a newer family of medications designated as disease-modifying anti-rheumatic drugs (DMARDs) has been developed. This medication has demonstrated an ability to change the course of RA for at least one year as evidenced by sustained improvement in function, decreased synovitis, and prevention of further joint damage [17]. Examples of these medications include parenteral gold salts, methotrexate, sulfasalazine, hydroxychloroquine (antimalarial drug), penicillamine, azathioprine, and leflunomide. A major drawback in the use of DMARDs is their considerable toxicity [18].

The use of DMARDs for the management of periodontitis has been restricted largely due to the toxicity issues. However, the use of gold salts in an animal model has shown reduced periodontal destruction [19]. Till now, no human studies have been performed.

The relationship between rheumatoid arthritis (RA) and periodontitis is controversial. Many studies that have been done present conflicting results regarding the relationship between periodontitis and RA. However, a significant association between these two common chronic diseases has been reported recently $[20,21]$.

RA is a common disease in Sudan, [22] and the literature correlating the severity of RA and the severity of periodontal disease is insufficient. This study was designed to investigate the periodontal status and in RA patients and to find if there is an association between RA and periodontal disease among patients in Khartoum State.

\section{Methods}

Eighty Rheumatoid arthritis patients (RA) aged $20-60$ years old were examined at the common rheumatoid arthritis clinics in Khartoum State (University of Medical Sciences and Technology, Elribat University Hospital and Ibrahim Malik Teaching Hospital). All patients had intertmittently been taking various kinds of NSAIDs for long periods, some of them occasionally in conjunction with chloroquines. A group of eighty healthy individuals matched in age and gender was selected as a control 
group from co-patients and employees in the same centers.

\section{Inclusion criteria \\ Study group}

- Patients (20-60 years old) diagnosed with RA with consideration of the disease duration.

- Willingness of the patient to participate in the study.

- Only partially (at least 8 teeth excluding $3^{\text {rd }}$ molar) or fully dentate patients were included in the study.

\section{Control group}

- Age group 20 - 60 years old

- Absence of rheumatoid arthritis, diabetes, hypertension and blood dyscriasis. This was determined by testing random blood sugar levels, measuring the blood pressure and doing a complete blood count for each patient prior to the examination.

- Willingness to participate in the study

- Only partially (at least eight teeth, excluding $3^{\text {rd }}$ molar) or fully dentate patients were selected in the control group.

Exclusion criteria included pregnancy, lactation, smoking, periodontal therapy or antibiotics in the previous three months, or any systemic condition which might have affected the progression of periodontitis. No subjects with localized or generalized aggressive periodontitis were included in this study.

Each subject who met the inclusion criteria completed a questionnaire, which gathered information on their demographic background. Approval for the research was obtained from the Research Ethics Committee of the Faculty of Dentistry University of Khartoum. Aims of the investigation and the nature of the study were fully explained to the subjects, who gave their informed written consent before participation.

All periodontal examinations were made with Michigan $\mathrm{O}$ periodontal probes with a controlled force of $0.2 \mathrm{~N}$ by one examiner (Kamil S). Clinical measurements were made at four sites (mesiobuccal-distobuccal), (mesio lingual-distolingual) of all teeth, excluding third molars. Plaque Index (PI) [23] and Gingival Index (GI) [24] were used for detection of plaque and gingival inflammation respectively. Michigan $\mathrm{O}$ periodontal probe was used for measurement of pocket depth and clinical attachment level.

\section{Statistical analysis}

Standard descriptive statistical techniques were used to summarize and present sample information. To check for possible significant differences in periodontal status between the case and control group, the t-test was used for normally distributed data. In case of non-normal data, the Mann-Whitney test was used. The data was processed using STATA software package (version10).

\section{Results}

The data of this study was collected over a period of five months from three rheumatoid arthritis centers in Khartoum State. The results revealed that there were no significant differences in plaque and gingival index among study and control, with mean plaque index of (1.25 \pm $0.4)$ for patients and $(1.17 \pm 0.28)$ for the control group $(\mathrm{p}=0.3597)$. The mean gingival index was $(1.2 \pm 0.24)$ for the patients and $(1.2 \pm 0.33)$ for the control $(\mathrm{p}=$ 0.3049) (Figure 1, 2).

There was a statistically significant difference in the mean pocket depth between the study and the control group, a mean pocket depth of $>4 \mathrm{~mm}$ was observed in $10 \%$ of subjects in the RA group compared to $1.25 \%$ in the control group (table 1).

The results showed statistically significant differences in clinical attachment loss between study and control groups, with mean clinical attachment loss of (1.03 \pm $0.95)$ for the study group and $(0.56 \pm 0.63)$ for the control group $\mathrm{p}=0.0002$ (table-2).

From the study, there was no significant correlation between duration of illness and plaque index ( $\mathrm{p}=$ $0.9786)$, gingival index $(\mathrm{p}=0.9079)$, and clinical attachment loss $(p=0.0933)$ at 0.05 level of significance (table-3).

The study also revealed that no association exists between the drugs used to treat rheumatoid arthritis (NSAIDs \& DMARDs) and the periodontal parameters (plaque index, gingival index, probeable pocket depth and clinical attachment loss) (table-4).

\section{Discussion}

In this study, 72 females and 8 males participated (9:1). This ratio is greater than previous studies in other

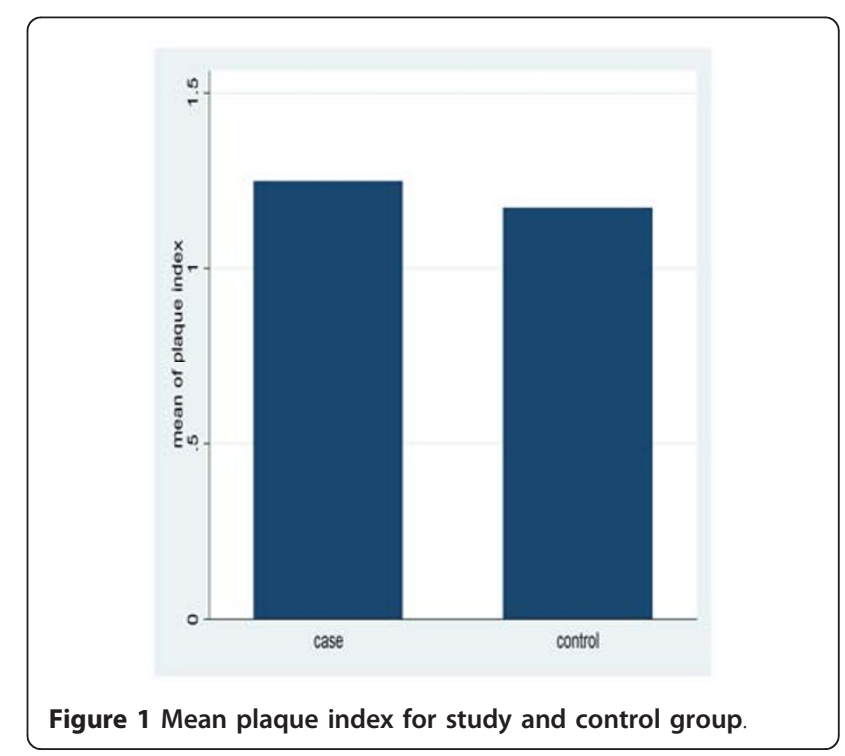


Table 2 Comparison of clinical attachment loss (per millimeters) between study group and control group

\begin{tabular}{llll}
\hline & Cases $(\mathbf{N}=\mathbf{8 0})$ & Controls $(\mathbf{N}=80)$ & P Value $^{*}$ \\
\hline$\leq 1.17$ & $52(65 \%)$ & $70(87.5 \%)$ & 0.006 \\
$>1.17$ to $\leq 2.33$ & $20(25 \%)$ & $7(8.75 \%)$ & \\
$>2.33$ to $\leq 3.5$ & $5(6.25 \%)$ & $3(3.75 \%)$ & \\
$>3.5$ & $3(3.75 \%)$ & $0(0 \%)$ & 0.0002 \\
\hline Mean \pm SD & $1.03 \pm 0.95$ & $0.56 \pm 0.62$ & \\
\hline
\end{tabular}

in the RA patients. These results agreed with Mercado et al [21], Mikael et al [29], N pischon et al [8] and Yniv et al [26].

A significant difference has been observed in the clinical attachment level of study and control groups 1 ( $\mathrm{p}=$ 0.002). The results agree with Ishi et al [27], Mikael et al [29] and Depablo et al, [30] and this may be due to increased secretion of pro-inflammatory mediators in both conditions.

Our findings showed that a relationship may exist between periodontitis and RA. This association is probably due to a common dysregulation of the immuneinflammatory response in these patients, despite their different etiology. In both conditions, there are a number of possible pathways of similar dysregulation, including characteristics of innate and acquired immune systems. Neutrophils play an important role in the pathogenesis of both diseases, and an aberrant neutrophilic response has been described, RA and periodontitis [31]. Another common pathogenic link affecting periodontitis and RA is the monocytic hypersecretory state [11], which may induce the secretion of excessive proinflammatory cytokine secretion, such as IL-1b, TNF-a and IL-6, which results in the stimulation of degrading enzymes and tissue destruction. The role of helper $\mathrm{T}$ lymphocytes has also been evaluated [32], it has been suggested that $\mathrm{T}$-cell characteristics in periodontal diseases may resemble, in some respects, those in RA, a condition in which tissue destruction is mediated by a $\mathrm{T}$ helper 1 (Th1) cytokine profile. Some studies point to a genetic component in the susceptibility to RA and periodontitis. Associations with HLA subtypes and genes outside the HLA region, such as genetic polymorphisms of some cytokines, may contribute to susceptibility to both diseases $[33,34]$.

This study shows no association between the drugs used for treatment of rheumatoid arthritis (NSAIDs \& DMARDs) and the periodontal parameters (plaque index, gingival index, and clinical attachment loss). This agreed with findings of Gleissner et al [35], who found no correlation between the duration of pharmacotherapy and periodontal parameters, but it disagreed with Ezel et al [28] who found that medication including NSAIDs and corticosteroids may decrease gingival inflammation. 
Table 3 Association between RA drugs and periodontal parameters

\begin{tabular}{|c|c|c|c|c|}
\hline & Plaque Index & Gingival Index & Probeable Pocket Depth & Clinical Attachment Depth \\
\hline NSAIDs & NA & NA & NA & NA (0.674) \\
\hline$P$ Value & $(0.718)$ & $(0.343)$ & $(0.228)$ & \\
\hline Steroids & NA & NA & NA & NA (0.981) \\
\hline$P$ Value & $(0.812)$ & $(0.932)$ & $(0.747)$ & \\
\hline Pencilliamine & NA & NA & NA & NA (0.776) \\
\hline$P$ Value & $(0.288)$ & $(0.198)$ & $(0.776)$ & \\
\hline Methiotrxate & NA & NA & NA & NA (0.483) \\
\hline$P$ Value & $(0.738)$ & $(0.415)$ & $(0.301)$ & \\
\hline Hydroxychloroquirie & NA & NA & NA & NA $(0.563)$ \\
\hline$P$ Value & $(0.192)$ & $(0.254)$ & $(0.563)$ & \\
\hline Sulphasalazine & NA & NA & NA & NA $(0.590)$ \\
\hline$P$ value & $(0.944)$ & $(0.569)$ & $(0.837)$ & \\
\hline
\end{tabular}

NA no association

P-value is measured by chi-square test

Table 4 Relationship between duration of illness and periodontal parameters

\begin{tabular}{lllll}
\hline & Plaque index & Gingival index & Pocket depth & Clinical attachment loss \\
\hline Duration of illness & $p$-value (0.9786) & p-value (0.9079) & $p$-value (0.5978) & $p$-value (0.0933) \\
\hline
\end{tabular}

There was no significant association between the duration of illness and periodontal destruction, although many RA patients take medications that can reduce periodontal destruction (i.e., NSAIDs). This may indicate that prior to the development of RA symptoms, the periodontitis was most likely developing and not detected.

\section{Conclusion}

The results indicated a significant relationship between periodontal disease and RA. However no significant difference between plaque and gingival index has been detected among study and control groups. This study highlights the potential for a relationship between two of the most common and debilitating chronic inflammatory conditions affecting the Sudanese population and warrants further detailed investigation.

\section{Abbreviations}

RA: Rheumatoid Arthritis; NSAIDs: Non steroidal anti-inflammatory drugs; DMARDs: Disease Modifying Anti Rheumatoid Drugs; HLA: Human Leukocyte Antigen; Pl: Plaque Index; Gl: Gingival Index.

\section{Acknowledgments}

We are grateful to the staff of the medical department of The Academic Technology Teaching Hospital, Elribat University Hospital and Ibrahim Malik Teaching Hospital. Special appreciation to all patients who allowed us to include them in this study. Also we are indebted to Kerry Corbett and Suzan Elamin for reviewing and editing the English language.

\section{Author details}

${ }^{1}$ Department of periodontology, School of Dentistry, Elneilein University, Khartoum, Sudan. ${ }^{2}$ Department of Periodontology, Khartoum North Dental Teaching Hospital, Khatroum, Sudan. ${ }^{3}$ Department of rheumatology, Faculty of Medicine, University of Medical Sciences and Technology, Khartoum,
Sudan. ${ }^{4}$ Department of Oral Rehabilitation, Faculty of Dentistry, University of Khartoum, Khartoum, Sudan.

\section{Authors' contributions}

SKA designed the study and carried out the data collection and the data analysis, BGG and EME supervised the research, NTH writing/editing of the article with assistant of BGG. All authors have read and approved the final manuscript.

\section{Competing interests}

The authors declare that they have no competing interests.

Received: 26 June 2011 Accepted: 28 October 2011

Published: 28 October 2011

\section{References}

1. Long GRichard, Hlousek Lubor, And john LDoyle: Oral manifestation of systemic diseases. 1998, 65(5 and 6):309-15.

2. Mercado FB, Marc hall R, Bartold PM: Inter-relationship betweenRA and periodontal disease a review. J clin periodontal 2003, 30:761-772.

3. Bartold PM, Marchall RI, Haynes DR: Periodontitis and RA a review. J periodontal 2005, 76:2066-2074.

4. Symmons DP: Epidemiology of rheumatoid arthritis: Determinants of onset, persistence and outcome. Best Pract Res Clin Rheumatol 2002, 16:707-722.

5. Symmons DP, Barrett EM, Bankhead CR, Scott DG, Silman AJ: The incidence of rheumatoid arthritis in the United Kingdom: Results from the Norfolk Arthritis Register. Br J Rheumatol 1994, 33:735-739.

6. Lee DM, Weinblatt ME: Rheumatoid arthritis. Lancet 2001, 358:903-911.

7. Treister Nanthaniel, Glick Michael: RA review and suggested dental care considerations. J Am Dent Assoc 130(5):689-698.

8. Pischon N, Pischon T, J Kroger E, Glumez BM, Kleber JP, Bernimoulin H, Landau PG, Prinkman P, Schlattman J, Zernicke F, Detert j: Association among RA, oral hygiene and Periodontitis. J Periodontol 2008, 79:979-986.

9. Arend WP, Dayer JM: Cytokines and cytokine inhibitors or antagonists in rheumatoid arthritis. Arthritis Rheum 1990, 33:305-315.

10. Hirschfeld L, Wasserman B: a long -term survey of tooth loss in 600 treated periodontal patients. J periodontol 1978, 49:225-237.

11. O'Sullivan JB, Cathcart ES: The prevalence of rheumatoid arthritis. Follow up evaluation of the effect of criteria on rates in Subury, Massachusetts. Ann Intern Med 1972, 76:573-577. 
12. Pincus T, Marcum SB, Callahan LF: Long-term drug therapy for rheumatoid arthritis in seven rheumatology private practices: II. Second line drugs and prednisone. J Rheumatol 1992, 19:1885-1894.

13. Wolfe F, Hawley DJ, Cathey MA: Termination of slow acting antirheumatic therapy in rhematoid arthritis: A 14-year prospective evaluation of 1017 consecutive starts. J Rheumato/ 1990, 17:994-1002

14. Lipsky PE: Rheumatoid arthritis. In Harrison's Principles of Internal Medicine 12 edition. Edited by: Wilson JD, Braunwald E, Isselbacher KJ, et al.. New York: McGraw- Hill; 1991:1437-1443.

15. Feldman RS, Szeto B, Chauncey HH, Goldhaber P: Non-steroidal antiinflammatory drugs in the reduction of human alveolar bone loss. J Clin Periodontol 1983, 10:131-136.

16. Williams RC, Jeffcoat MK, Howell TH, et al: Altering the progression of human alveolar bone loss with the non-steroidal anti-inflammatory drug flurbiprofen. J Periodontol 1989, 60:485-490.

17. Paget S: Treatment. In Primer on the Rheumatic Diseases. Edited by: Klippel J. Atlanta: Arthritis Foundation; 1997:168-174

18. American College of Rheumatology Ad Hoc Committee on Clinical Guidelines: Guidelines for monitoring drug therapy in the management of rheumatoid arthritis. Arthritis Rheum 1996, 39:723-731.

19. Novak MJ, Polson AM, Freeman E: Effects of gold salts on experimental periodontitis. I. Histometric evaluation of periodontal destruction. $J$ Periodontol 1984, 55:69-77.

20. Mercado F, Marshal R, Klestov A, Bartold P: Is there a relationship between rheumatoid arthritis and periodontal disease? Journal of Clinical Periodontology 2000, 27:267-272.

21. Mercado F, Marshal R, Klestov A, Bartold P: A relationship between rheumatoid arthritis and periodontal disease. Journal of Periodontology 2001, 72:779-787.

22. Muaz AM: Presentation and manifestation of patients with sero-positive RA in Khartoum State.2003-2004.

23. Silness J, Löe H: Periodontal disease in pregnancy II. Correlation between oral hygiene and peiodontal condition. Acta Odontol Scand 1964, 22:121-135.

24. Löe $\mathrm{H}$ : The gingival index, the plaque index and the retention index systems. J Periodontol 1967, 38:610-616.

25. Harris ED Jr: Clinical features of rheumatoid arthritis. In Textbook of rheumatology.. 5 edition. Edited by: Kelly WN, Harris ED, Sledge CB. Philadelphia: WB Saunders; 1997:898.

26. Mayer Yaniv, Balbir- Gurman Alexandra, Eli E, Machtei : Anti TNF alpha therapy and periodontal parameters in RA patients. J Periodontology 2009.

27. Ishi Ede P, Bertolo MB, Bossa C Jr, Kirkwood KL: Periodontal condition in patients with RA. OnofrM. Braz Oral Res 2008, 22(1):72-7.

28. Ezel B, Sule B, Selami A, Fatima B: Relationship between IL-6 levels in GCF and periodontal status in patients with adult Periodontitis. $J$ Periodontology 2000, 71(11):1756-1760.

29. Mikael N, Sigvard K: Gingivitis and Periodontitis Are related to repeated high levels of circulating TNF alpha In patients with RA. J Periodontol 2008, 79:1689-1696.

30. de Pablo P, Dietrich T, Mc Alindon TE: Association of periodontal disease and tooth loss with RA in the US population. J Periodontol 2008, 79(9):1645-51

31. Figueredo CM, Gustafsson A: Activity and inhibition of elastase in GCF. Journal of Clinical Periodontology 1999, 25:531-535.

32. Taubman MA, Kawai T: Involvement of T-lymphocytes in periodonta disease and in direct and indirect induction of bone resorption. Critical Reviews Oral Biology and Medicine 2001, 12:125-135.

33. Takashiba S, Ohyama H, Oyazu K, Kogoe- Kato N, Murayama Y: HLA genetics for diagnosis of susceptibility to early onset periodontitis. Journal of Periodontal Research 1999, 34:374-378.

34. Michel J, Gonzales JR, Wunderlich D, Diete A, Herrmann JM, Meyle J: Interleukin-4 polymorphisms in early onset periodontitis. Journal of Clinical Periodontology 2001, 28:483-488.

35. Gleissner C, Willershausen B, Kaesser U, Bolten WW: The role of risk factors for periodontal disease in patients with RA. Eur J Med 1998, 3(8):387-92.

doi:10.1186/1756-0500-4-460

Cite this article as: Abdelsalam et al:: Periodontal status of rheumatoid arthritis patients in khartoum state. BMC Research Notes 2011 4:460.

\section{Submit your next manuscript to BioMed Central and take full advantage of:}

- Convenient online submission

- Thorough peer review

- No space constraints or color figure charges

- Immediate publication on acceptance

- Inclusion in PubMed, CAS, Scopus and Google Scholar

- Research which is freely available for redistribution

Submit your manuscript at www.biomedcentral.com/submit 